\title{
The effects of increased dose of exercise-based therapies to enhance motor recovery after stroke: a systematic review and meta-analysis
}

\author{
Emma V Cooke ${ }^{1}$, Kathryn Mares ${ }^{2}$, Allan Clark ${ }^{3}$, Raymond C Tallis ${ }^{4}$, Valerie M Pomeroy ${ }^{2 *}$
}

\begin{abstract}
Background: Exercise-based therapy is known to enhance motor recovery after stroke but the most appropriate amount, i.e. the dose, of therapy is unknown. To determine the strength of current evidence for provision of a higher dose of the same types of exercise-based therapy to enhance motor recovery after stroke.

Methods: An electronic search of: MEDLINE, EMBASE, CINHAL, AMED, and CENTRAL was undertaken. Two independent reviewers selected studies using predetermined inclusion criteria: randomised or quasi randomised controlled trials with or without blinding of assessors; adults, 18+ years, with a clinical diagnosis of stroke; experimental and control group interventions identical except for dose; exercise-based interventions investigated; and outcome measures of motor impairment, movement control or functional activity. Two reviewers independently extracted outcome and follow-up data. Effect sizes and 95\% confidence intervals were interpreted with reference to risk of bias in included studies.
\end{abstract}

Results: 9 papers reporting 7 studies were included. Only 3 of the 7 included studies had all design elements assessed as low risk of bias. Intensity of the control intervention ranged from a mean of 9 to 28 hours over a maximum of 20 weeks. Experimental groups received between 14 and 92 hours of therapy over a maximum of 20 weeks. The included studies were heterogeneous with respect to types of therapy, outcome measures and timepoints for outcome and follow-up. Consequently, most effect sizes relate to one study only. Single study effect sizes suggest a trend for better recovery with increased dose at the end of therapy but this trend was less evident at follow-up Meta-analysis was possible at outcome for: hand-grip strength, -10.1 [-19.1,-1.2] (2 studies, 97 participants); Action Research Arm Test (ARAT), 0.1 [-5.7,6.0] (3 studies, 126 participants); and comfortable walking speed, 0.3 [0.1,0.5] (2 studies, 58 participants). At follow-up, between 12 and 26 weeks after start of therapy, metaanalysis findings were: Motricity Arm, 10.7 [1.7,19.8] (2 studies, 83 participants); ARAT, 2.2 [-6.0,10.4] (2 studies, 83 participants); Rivermead Mobility, 1.0 [-0.6, 2.5] (2 studies, 83 participants); and comfortable walking speed, 0.2 [0.0,0.4] (2 studies, 60 participants).

Conclusions: Current evidence provides some, but limited, support for the hypothesis that a higher dose of the same type of exercised-based therapy enhances motor recovery after stroke. Prospective dose-finding studies are required.

\section{Background}

Exercise-based therapy is known to enhance motor recovery after stroke but the most appropriate amount, i.e. the dose, of therapy is unknown. There is strong clinical opinion that if higher doses of exercise-based

\footnotetext{
* Correspondence: v.pomeroy@uea.ac.uk

${ }^{2}$ Health and Social Sciences Research Institute, Queen's Building, University of East Anglia, Norwich, NR4 7TJ, UK

Full list of author information is available at the end of the article
}

therapy could be provided then motor outcome would be improved.

The possibility of a dose-response relationship between exercise-based therapy and motor recovery is supported by the findings of several systematic reviews [1-5]. However, some of the included trials in all of the published systematic reviews were not designed primarily to evaluate different doses of the same therapy. Rather, they were designed to evaluate either different types of therapy, augmentation of one therapy with

\section{() Biomed Central}


another or even the effects of a therapy compared with no treatment. Consequently, the results of these systematic reviews are confounded by examination of different types as well as different intensities of therapies. Differentiation of the effects of different types and different intensities of exercise-based therapies is required.

In contrast to widely-held clinical opinion and conclusions of systematic reviews an increased dose of constraint-induced movement therapy (CIMT) given early after stroke resulted in a worse outcome than either a smaller dose of CMIT or a smaller dose of conventional therapy [6]. This unexpected finding echoes those from animal model studies which indicate that a high usage of a paretic forelimb early after experimental stroke is associated with a poorer motor outcome and an increase in size of the brain lesion [7-9] if it is provided early after stroke [10]. It is possible, therefore, that high doses of exercise-based therapy could be detrimental for motor recovery after stroke. This is not the only possibility, however, as experimental animal model studies indicate that more activity, provided in enriched environments, enhances motor recovery more than a standard housing environment [11]. In addition, preliminary investigation suggests the existence of a moderate relationship $(\mathrm{r}=0.45, \mathrm{p}<0.01)$ between the number of repetitions of an exercise and improvement in motor function [12], post-hoc analysis of three separate research studies of the same therapy suggests greater benefit for a higher dose [13] and an exploratory study suggests benefit from higher dose of CIMT for people who were later after stroke [14] than were participants in the recent trial [6].

Whether an increased dose of exercise-based therapy is beneficial, detrimental or makes no difference to motor recovery after stroke needs to be elucidated. Well designed studies of different doses of the same therapy at different times after stroke in well characterised groups of stroke survivors are required. Before undertaking such studies a systematic review specifically investigating the effect of increased dose of exercise therapy is required to establish the current evidencebase. This paper reports a systematic review and metaanalysis designed to determine the strength of current evidence for providing a higher intensity of the same types of exercise-based therapy to enhance motor recovery after stroke.

\section{Methods Design}

The design of this systematic review followed recommendations of the Cochane Collaboration. The review protocol was not published prior to this report other than as part of a PhD thesis [15].

\section{Search strategy}

The following databases were searched electronically; US National Library of Medicine Database (MEDLINE); European Medical Database (EMBASE); Cumulative Index to Nursing and Allied Health Literature (CINHAL); Allied and Complementary Medicine Database (AMED); and Cochrane Central Register of Controlled Trials (CENTRAL). An example of the search strategy used is given in Table 1. The initial search was conducted to cover the time period from induction of the databases to November 2008 and this was updated in a subsequent search to include the period up to October 2009. The updated search (December 2008 to October 2009) did not include CINHAL because the host had changed from OVID. A decision was made not to update the CINHAL search because records identified through it in the initial search were also found in other databases.

\section{Table 1 Search strategy for electronic databases}

\begin{tabular}{|c|c|}
\hline 1. exp Stroke/ & 34. 33 or 28 or 19 \\
\hline 2. stroke.mp. & 35. exercis\$.mp. \\
\hline 3. cerebrovascular diseas\$.mp. & 36. exercis\$.sh. \\
\hline 4. cerebral vascular diseas\$.mp. & 37. exp Exercise/ \\
\hline 5. cerebral vascular accident\$.mp. & 38. functional strength train\$.mp. \\
\hline 6. cerebrovascular accident\$.mp. & 39. activities of daily living.mp. \\
\hline 7. (hemipleg\$ or hemipar\$).mp. & 40. neuro facilitation.mp. \\
\hline 8.6 or 4 or 1 or 3 or 7 or 2 or 5 & 41. bobath therap\$.mp. \\
\hline 9. exp Physical Therapy & 42. motor relearn\$.mp. \\
\hline Modalities/ & 43. rehabilitation.mp. \\
\hline 10 physiotherapy.mp. & 44. rehabilitation.sh. \\
\hline 11. physical therapy.mp. & 45. exp Rehabilitation/ \\
\hline 12. 11 or 10 or 9 & 46. restoration of function\$.mp. \\
\hline 13. randomized controlled trial.pt. & 47.35 or 39 or 40 or 36 or 41 or 38 \\
\hline 14. controlled clinical trial.pt. & or 42 or 46 or 45 or 37 or 43 or 44 \\
\hline 15. randomised controlled trials.sh. & 48. intensit\$.mp. \\
\hline 16. random allocation.sh. & 49. intensit\$.sh. \\
\hline 17. double-blind method.sh. & 50. frequenc\$.sh. \\
\hline 18. single-blind method.sh. & 51. frequenc\$.mp. \\
\hline $\begin{array}{l}\text { 19. } 18 \text { or } 16 \text { or } 13 \text { or } 17 \text { or } 12 \text { or } \\
15 \text { or } 14\end{array}$ & $\begin{array}{l}\text { 52. duration.mp. } \\
\text { 53. duration.sh. }\end{array}$ \\
\hline 20. clinical trial.pt. & 54. dose.mp. \\
\hline 21. exp Clinical Trial/ & 55. dosage.mp. \\
\hline $\begin{array}{l}\text { 22. ((singl\$ or doubl\$ or treb\$ or } \\
\text { trip\$) adj25 (blind\$ or mask\$)).ti, } \\
\text { ab. }\end{array}$ & $\begin{array}{l}\text { 56. amount.mp. } \\
\text { 57. quantit\$.mp. } \\
\text { 58. how much.mp. }\end{array}$ \\
\hline 23. (clin\$ adj25 trial\$).ti, ab. & 59. dos\$.mp. \\
\hline 24. placebo\$.ti, ab. & 60. dosing.mp. \\
\hline 25. placebo.sh. & 61. doses.mp. \\
\hline 26. random\$.ti, ab. & 62. amounts.mp. \\
\hline 27. research design.sh. & 63. 63.50 or 53 or 57 or 61 or 51 \\
\hline $\begin{array}{l}\text { 28. } 27 \text { or } 25 \text { or } 21 \text { or } 26 \text { or } 20 \text { or } \\
22 \text { or } 24 \text { or } 23\end{array}$ & $\begin{array}{l}\text { or } 58 \text { or } 48 \text { or } 59 \text { or } 52 \text { or } 60 \text { or } \\
56 \text { or } 49 \text { or } 62 \text { or } 54 \text { or } 55\end{array}$ \\
\hline 29. comparative study.sh. & 64. 64.8 and 63 and 34 and 12 and \\
\hline 30. exp Evaluation Studies/ & 47 \\
\hline 31. follow up studies.sh. & \\
\hline $\begin{array}{l}\text { 32. (contro\$ or prospectiv\$ or } \\
\text { volunteer\$).ti, ab. }\end{array}$ & \\
\hline 33. 32 or 30 or 31 or 29 & \\
\hline
\end{tabular}

Abbreviations

$\mathrm{mp}=$ title, original title, abstract, name of substance word, subject heading word. 
Reference lists of all articles reporting included trials were searched for any extra possibly relevant records. If any records were identified from the hand searching of reference lists and they came from journals not included on the CENTRAL data base, the contents pages of those journals were hand searched. A hand search of our own private databases of references was also undertaken. In addition authors of included articles were contacted for any unpublished data.

\section{Criteria for inclusion of trials Types of trial}

Randomised or quasi randomised controlled trials with or without blinding of assessors;

\section{Types of participants}

Adults, aged over 18 years, with a clinical diagnosis of stroke

\section{Types of interventions}

- Experimental and control group interventions identical except for dose. Therapy dose can be described in terms of time spent in therapy and/or of effort expended [16]. Description of time includes: minutes per session; sessions per day/week; and number of days/weeks [16]. Description of effort can be made in terms of the work or power required to perform an exercise for example, resistance training and the amount of weight used [16]. For this systematic review dose refers to the total time spent in exercise-based therapy.

- Interventions investigated were exercise-based (no electrostimulation, splinting or orthotics) to facilitate muscle activity or functional ability;

\section{Types of outcome measures}

- Measure of motor impairment - muscle function. For example. Motricity Index, muscle tone, joint range of motion;

- Measures of motor impairment - movement control. For example. co-ordination, reaction time;

- Measure of motor activity. For example. Modified Rivermead Mobility Index, Action Research Arm Test, Functional Ambulation Categories, 9 Hole Peg Test.

\section{Trial selection}

The identification of relevant trials was undertaken by two reviewers independently using the pre-set inclusion criteria set out on a predesigned form. Reviewers assessed the record titles and categorised each as 'definitely relevant', 'possibly relevant' or 'definitely irrelevant'. Any title that both reviewers ranked 'definitely irrelevant' was excluded. The reviewers repeated the categorisation process for abstracts and full papers in turn. They did not use the category possibly relevant for the full papers. Any disagreements between the reviewers were resolved through referral to full papers and discussion. Trials reported in full papers which were categorised as 'definitely irrelevant' by both reviewers were excluded and reasons documented. Trials which both reviewers categorised as 'definitely relevant' were classified as included trials for evaluation in this systematic review.

\section{Assessment of risk of bias}

Assessment of the risk of bias in included trials was undertaken by two reviewers independently for design features using the tool developed by the Cochrane Collaboration [17]. Any disagreements between reviewers were resolved by discussion, referral to full papers and contact with authors for clarification where necessary. A risk of bias plot was produced for the review using categories of low, unclear or high risk.

\section{Data Extraction}

Data extraction was undertaken by two reviewers independently using a predesigned form. Any disagreements were resolved by discussion and referral to the original full papers. Trial authors were contacted to clarify results when this was necessary and possible. Data was extracted on:

- Trial design, sample size and attrition;

- Participant characteristics' e.g. age, gender, site of lesion, stroke classification;

- Type of interventions;

- Dose of interventions (sum of treatment hours);

- Measures made at outcome (end of intervention period) and follow-up time-points in terms of average scores for trial groups.

\section{Statistical analysis of outcome and follow-up data}

Analysis was undertaken, where possible, on an intention- to-treat basis. Trials were not excluded if data was unavailable for subjects who did not complete all the outcome measures. Data analysis was undertaken using the Cochrane statistical package RevMan 4.2.

Effect sizes were calculated as odds ratios (OR) and 95\% confidence interval (CI) for dichotomous outcomes and as weighted mean differences (WMD and 95\% CI) for continuous outcomes. WMDs were determined initially using a Fixed Effect Model. Where two or more trials had used the same outcome measure, however, and if there was evidence of heterogeneity, the WMDs were estimated from a Random Effects Model. Where it was not possible to combine and compare the outcome measures reported in different trials, then statistical results were described and tabulated individually. Subgroups were formed by each follow-up time point. No overall analysis was done since this would involve combining subgroups based on the same individuals and could bias the results. 


\section{Synthesis and interpretation}

The results of the statistical analysis were interpreted with reference to the risk of bias in trials, and comparability of participants, types of interventions and dose of interventions.

\section{Results}

Full details of the number of records screened and studies included in this review are given in Figure 1. In summary, 940 potentially relevant records were screened and 31 potentially relevant records were identified. Twenty-two records did not meet the inclusion criteria and are listed in Table 2 alongside the reasons for their omission from this review. The remaining nine records were articles reporting seven studies (three articles reported different aspects of the same study [17-19]. Therefore nine articles reporting seven studies have been included in this review [18-26] (Fig 1).

\section{Study designs}

Of the 7 included studies three used a multi-centre, observer-blind randomised controlled design. The remaining four studies used a single-centre, observerblind randomised controlled design (Table 3)

\section{Participants}

The seven studies included 680 participants (range 20189) who completed baseline measurements (Table 3).

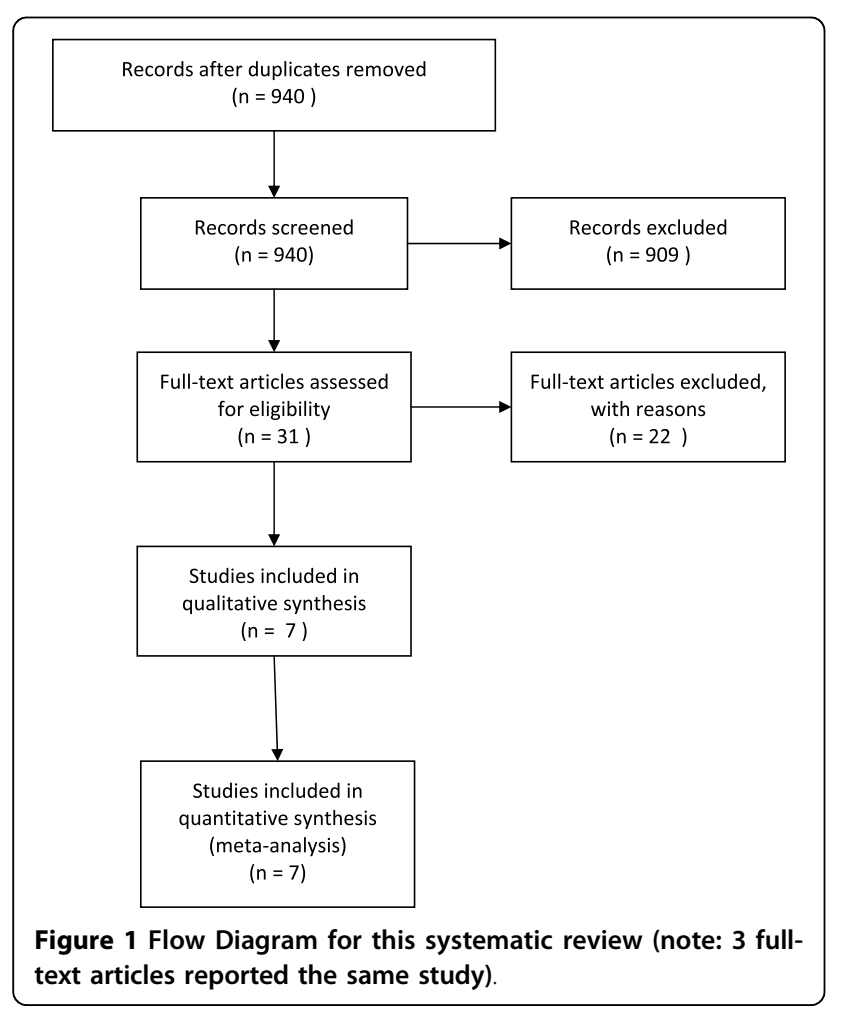

One trial provided additional therapy from a qualified therapist and an assistant, but only the subjects treated by the qualified therapist are included in this review to ensure comparability with the other studies [22]. The mean age of participants in the seven studies ranged from 65.9 years [18-20] to 76.5 years [22] and time since stroke on admission to studies ranged from a median of 5 days [24] to a mean of 35 days [26] (Table 3). Full details of participant characteristics are provided in Table 3.

\section{Interventions}

Four of the studies described the intervention as a 'normal movement' (Bobath) approach [21-24], two studies investigated conventional physical therapy as used in the UK $[25,26]$ and one study based the intervention on an eclectic approach involving task specific training regime following stroke [18-20] (Table 4). The dose of the exercise-based intervention was described in terms of intensity (minutes per day), frequency (times per week), duration (number of weeks). From this the total dose was calculated. The dose of the control intervention was not provided in two studies $[22,23]$. The dose of the control intervention in the remaining five studies ranged from a mean of 9.2 hours [26] to 27.5 hours [18-20]. The mean dose received by the experimental groups (control plus extra) ranged from 13.8 hours $[25]^{\mathrm{D}}$ to 91.8 hours [18-20]. Details are provided in Table 4.

\section{Assessment of potential bias}

The results of the assessment of potential bias are presented in Table 5 . In summary, only 3 of the 7 included studies had all design elements assessed as low risk of bias. Of note are:

1. The blinding procedure used in one study [24] was assessed as presenting a potential high risk of bias because in the discussion section of the paper it is stated that clinical therapists were not blind to treatment allocation and therefore gave more uni-disciplinary treatment to those participants who were receiving less therapy in the trial.

2. Allocation concealment procedures used in two studies [18-20,22] were unclear as there were no specific statements about this aspect of randomisation procedure e.g. use of sealed opaque envelopes

3. Incomplete outcome data is possibly present in two studies $[22,23]$ but this is unclear from information presented in the papers. In one trial [22] it was reported that a number of participants died yet there was no reference to the process used for analysis for drop outs. Indeed the results tables suggest that all participants were included in the outcome analysis. One trial [23] provided no reasons for withdrawals and no methods 
Table 2 Excluded Studies

\begin{tabular}{|c|c|}
\hline Study & Reason for Exclusion \\
\hline Ada 2006 & Not a randomised controlled trial. \\
\hline Barreca 2004 & Treatment interventions between control and experimental group differed in content. \\
\hline Dromerick 2009 & $\begin{array}{l}\text { Interventions included different time periods for wearing of mitt (not an exercise based intervention) and different doses of } \\
\text { shaping, therefore, unable to determine which aspect of this intervention would contribute to functional outcomes. }\end{array}$ \\
\hline Duncan 2003 & Treatment interventions between control and experimental group differed in content. \\
\hline Fang 2003 & $\begin{array}{l}\text { Control group received no intervention, therefore study investigated effects of physiotherapy rather than an increased intensity } \\
\text { of physiotherapy. }\end{array}$ \\
\hline Feys 1998 & Investigated the effects of an intervention not intensity. \\
\hline Fisher 2001 & Not a randomised controlled trial. \\
\hline Green 2002 & Investigated the effect of an intervention in a specific setting not intensity. \\
\hline Kuys 2008 & Not a randomised controlled trial. \\
\hline Kwakkel 2002 & Examination of a subgroup of the original trial (Kwakkel 1999). \\
\hline Moreland 2003 & Progressive resisted exercise - not the definition of intensity used in this review. \\
\hline Nugent 1994 & Not a controlled or randomised controlled trial. \\
\hline Page 2004 & Investigated the effect of an intervention not intensity. \\
\hline Richards1993 & Treatment interventions between control and experimental group differed in content. \\
\hline Richards 2008 & Not a randomised controlled trial. \\
\hline Sivenius 1985 & $\begin{array}{l}\text { Extra therapy incorporated components of physical, occupational and speech therapy. It was not possible to isolate the effects } \\
\text { of exercise-based therapy. }\end{array}$ \\
\hline Slade 2002 & $\begin{array}{l}\text { Therapy analysed included physical, perceptual and cognitive, washing and dressing, daily living activities, group treatment, joint } \\
\text { treatment and splinting and this was analysed as 'a package'. It was not possible to isolate the effects of exercise-based therapy. }\end{array}$ \\
\hline Smith 1981 & $\begin{array}{l}\text { No specific treatment techniques described. Intensive therapy involved multi disciplinary treatment and therefore difficult to } \\
\text { isolate the effects of exercise-based therapy. Control group also given extra treatment if deemed necessary. }\end{array}$ \\
\hline Sunderland 1992 & $\begin{array}{l}\text { Treatment interventions between control and experimental group differed in content. The experimental group also included } \\
\text { EMG biofeedback. }\end{array}$ \\
\hline Wade 1992 & $\begin{array}{l}\text { Subjects received physiotherapy immediately or after three months delay, therefore effectively the first half of a crossover study } \\
\text { - physiotherapy versus no treatment. Therefore not different intensities of the same physiotherapy treatment. }\end{array}$ \\
\hline Werner 2002 & Treatment interventions between control and experimental group differed in content. \\
\hline Wolf 2007 & Not a randomised controlled trial. \\
\hline
\end{tabular}

for dealing with participants who withdrew before measurement time-points.

4. One trial appeared to report outcomes selectively [23]. Specifically step-time ratio was included in list of outcomes to be measured yet was not reported in the results section. Also sit-to-stand time, timed walk and functional reach were not measured at baseline yet there was no explanation as to why these were omitted.

\section{Outcomes}

Extraction of data for one study [18-20] was undertaken considering its 3-group design of placebo, extra arm therapy and extra leg therapy and that all participants undertook all measures. In this present review we considered that the placebo group would act as a control for both experimental groups but that data extracted for the arm group would be that specific to the upper limb and data extracted for the leg group would be that specific to the lower limb. Consequently data analysed in this present review does not include upper limb measures reported for the leg group and vice versa. Two other studies also used a 3 -group design [25,26] to compare different types and different doses of physical therapy. The data extracted from these for this review consists of that for the groups receiving the routine amount and extra amount of conventional physical therapy.

The time-points for outcome measures were mostly comparable as they were made between 4 and 6 weeks after the start of therapy except for one study where treatment was provided for 20 weeks [18-20] (Table 4) At follow-up 1 there was more variety between studies with time-points ranging from 12 to 26 weeks after the start of treatment and also 3 months after stroke (Table 4). Follow-up 2 time-points were either 6 months after start of treatment, 52 weeks after start of treatment or 6 months after stroke (Table 4).

1. Motor impairment - muscle function (Table 6)

Heterogeneity between studies in use of specific measures limited meta-analysis. At outcome there was a trend towards benefit for a higher dose of therapy but effect sizes for 5 of the 10 comparisons were not statistically significant. Significant effect 
Table 3 Included studies design, participants and attrition

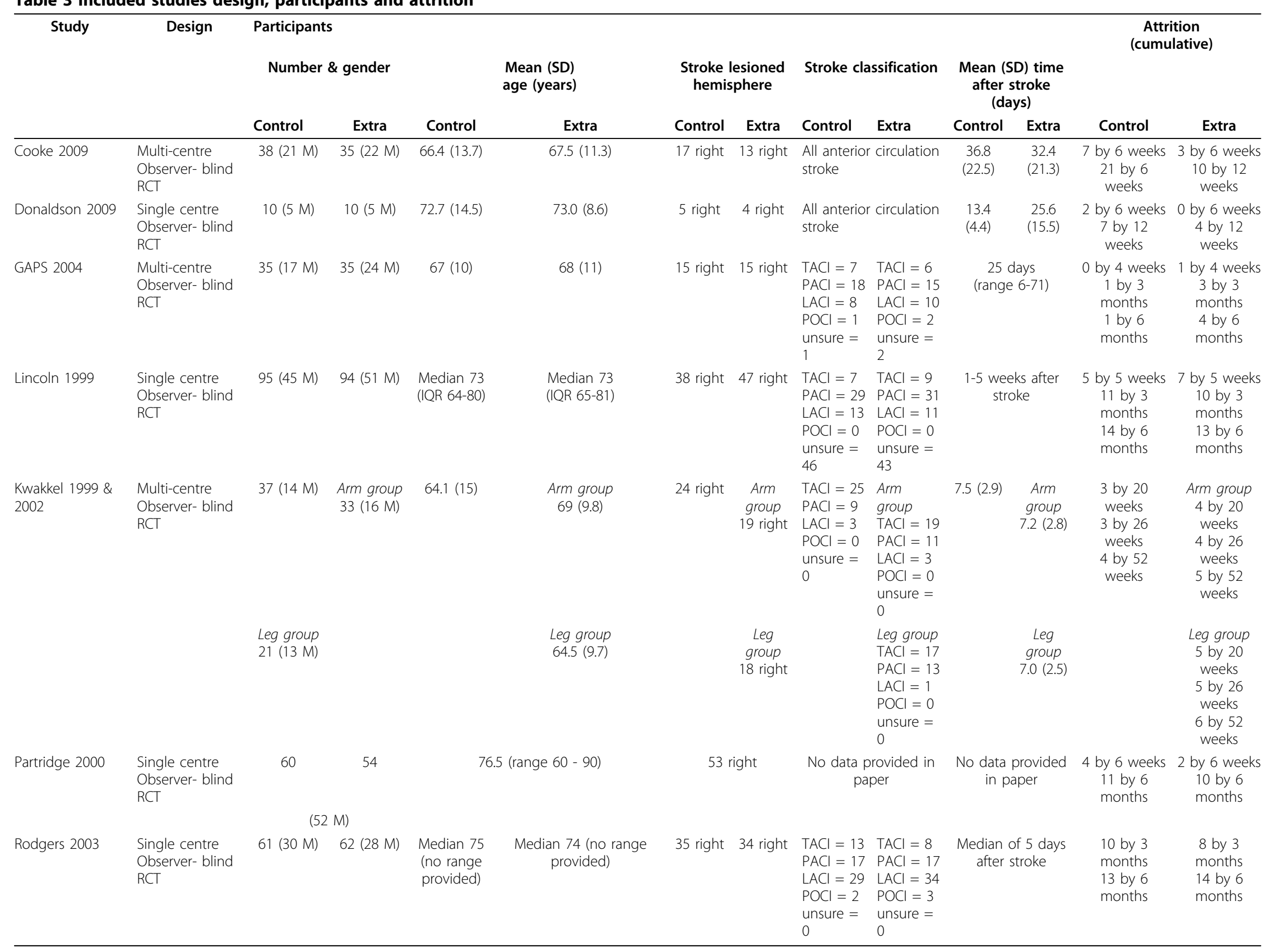




\begin{tabular}{|c|c|c|c|c|c|c|c|c|}
\hline \multirow[t]{2}{*}{ Study } & Intervention & \multicolumn{2}{|c|}{$\begin{array}{l}\text { Intensity - mean hours } \\
\text { delivered (SD) }\end{array}$} & \multirow[b]{2}{*}{ Baseline } & \multicolumn{2}{|c|}{ Measurement time points } & \multirow[b]{2}{*}{ Follow-up 2} & \multirow[t]{2}{*}{ Outcome measures } \\
\hline & Control & Control & Extra & & Outcome & Follow-up 1 & & \\
\hline \multirow[t]{2}{*}{ Cooke 2009} & $\begin{array}{l}\text { Conventional physical therapy - } \\
\text { lower limb from usual staff }\end{array}$ & $\begin{array}{c}9.2 \\
(6.9)\end{array}$ & $23.0(10.4)$ & $\begin{array}{l}\text { Pre- } \\
\text { intervention }\end{array}$ & $\begin{array}{l}\text { After } 6 \text { weeks of } \\
\text { intervention }\end{array}$ & $\begin{array}{l}12 \text { weeks after end } \\
\text { treatment }\end{array}$ & NA & $\begin{array}{l}\text { - Walking speed } \\
\text { - Ability to walk at } 0.8 \mathrm{~m} / \mathrm{s} \\
\text { or more } \\
\text { - Modified Rivermead } \\
\text { Mobility Index } \\
\text { - Knee flexion peak torque } \\
\text { - Knee extension peak } \\
\text { torque }\end{array}$ \\
\hline & Extra from research staff & & & & & & & \\
\hline \multirow[t]{2}{*}{$\begin{array}{l}\text { Donaldson } \\
2009\end{array}$} & $\begin{array}{l}\text { Conventional physical therapy - } \\
\text { upper limb from usual staff }\end{array}$ & $\begin{array}{l}2.81 \\
(3.7)\end{array}$ & $\begin{array}{l}13.8 \\
(27.1)\end{array}$ & $\begin{array}{l}\text { Pre- } \\
\text { intervention }\end{array}$ & $\begin{array}{l}\text { After } 6 \text { weeks of } \\
\text { intervention }\end{array}$ & $\begin{array}{l}12 \text { weeks after end } \\
\text { treatment }\end{array}$ & & $\begin{array}{l}\text { - Action Research Arm Test } \\
\text { - } 9 \text { hole peg test } \\
\text { - Hand grip force } \\
\text { - Pinch grip force } \\
\text { - Elbow flexion force - } \\
\text { isometric } \\
\text { - Elbow extension force - } \\
\text { isometric }\end{array}$ \\
\hline & Extra from research staff & & & & & & & \\
\hline GAPS 2004 & $\begin{array}{l}\text { Treatment broadly based on } \\
\text { 'normal movement' (Bobath } \\
\text { approach) from usual staff. }\end{array}$ & $\begin{array}{l}\text { Average } \\
21 \\
\text { (no } \\
\text { data) }\end{array}$ & $\begin{array}{l}\text { Average } 34 \\
\text { (no data) }\end{array}$ & $\begin{array}{l}\text { Pre- } \\
\text { intervention }\end{array}$ & $\begin{array}{l}\text { After } 4 \text { weeks of } \\
\text { intervention }\end{array}$ & $\begin{array}{l}3 \text { months after start } \\
\text { treatment }\end{array}$ & $\begin{array}{l}6 \text { months after start } \\
\text { treatment }\end{array}$ & $\begin{array}{l}\text { - Rivermead Mobility Index } \\
\text { - Motricty Index }\end{array}$ \\
\hline \multirow[t]{2}{*}{ Lincoln 1999} & $\begin{array}{l}\text { Treatment based on the Bobath } \\
\text { approach from usual staff }\end{array}$ & No data & $\begin{array}{l}\text { Median } 9.58 \text { extra } \\
\text { to control } \\
\text { (IQR } 4.7-10)\end{array}$ & $\begin{array}{c}\text { Pre- } \\
\text { intervention }\end{array}$ & $\begin{array}{l}\text { After } 5 \text { weeks of } \\
\text { intervention }\end{array}$ & $\begin{array}{l}3 \text { months after start } \\
\text { treatment }\end{array}$ & $\begin{array}{l}6 \text { months after start } \\
\text { treatment }\end{array}$ & $\begin{array}{l}\text { - Rivermead Arm } \\
\text { Assessment } \\
\text { - Action Research Arm Test } \\
\text { - Rivermead Motor Assess - } \\
\text { gross function } \\
\text { - } 10 \text {-hole Peg Teat } \\
\text { - Maximum grip strength }\end{array}$ \\
\hline & Extra from research staff & & & & & & & \\
\hline \multirow[t]{2}{*}{$\begin{array}{l}\text { Kwakkel } 1999 \\
\& 2002\end{array}$} & $\begin{array}{l}\text { Routine arm \& leg training using } \\
\text { evidenced-based guidelines from } \\
\text { usual staff }\end{array}$ & $\begin{array}{l}27.5 \mathrm{arm} \\
\& \\
23.2 \text { leg* }^{*}\end{array}$ & $\begin{array}{l}\text { Arm group } \\
91.8^{*}\end{array}$ & $\begin{array}{c}\text { Pre- } \\
\text { intervention }\end{array}$ & $\begin{array}{l}\text { After } 20 \text { weeks } \\
\text { treatment }\end{array}$ & $\begin{array}{l}26 \text { weeks after start } \\
\text { treatment }\end{array}$ & $\begin{array}{l}52 \text { weeks after start } \\
\text { treatment }\end{array}$ & $\begin{array}{l}\text { Arm group } \\
\text { - Action Research Arm Test } \\
\text { - Frenchay Activities Index }\end{array}$ \\
\hline & $\begin{array}{c}\text { Arm group } \\
\text { Arm training from usual } \\
\text { staffLeg group } \\
\text { Leg training from usual } \\
\text { staff }\end{array}$ & leg* & $\begin{array}{l}\text { Leg group } \\
84.2^{*}\end{array}$ & & & & & $\begin{array}{l}\text { Leg group } \\
\text { - Comfortable walking speed } \\
\text { - Maximum walking speed } \\
\text { - Functional Ambulation } \\
\text { Categories }\end{array}$ \\
\hline Partridge 2000 & $\begin{array}{l}\text { Bobath method of treatment from } \\
\text { usual staff }\end{array}$ & No data & No data & $\begin{array}{l}\text { Pre- } \\
\text { intervention }\end{array}$ & $\begin{array}{l}\text { After } 6 \text { weeks of } \\
\text { intervention }\end{array}$ & $\begin{array}{l}6 \text { months after start } \\
\text { treatment }\end{array}$ & NA & $\begin{array}{l}\text { - Functional reach } \\
\text { - 5-metre timed walk } \\
\text { - Timed sit-to-stand }\end{array}$ \\
\hline Rodgers 2003 & $\begin{array}{l}\text { Normal movement approach } \\
\text { (Bobath) within meaningful activity } \\
\text { and task analysis from usual staff }\end{array}$ & 17.4 & 24.9 & $\begin{array}{l}\text { Pre- } \\
\text { intervention }\end{array}$ & None & $\begin{array}{l}3 \text { months after } \\
\text { stroke }\end{array}$ & $\begin{array}{l}6 \text { months after } \\
\text { stroke }\end{array}$ & $\begin{array}{l}\text { - Action Research Arm Test } \\
\text { - Upper Limb Motricity Index } \\
\text { - Frenchay Arm Test }\end{array}$ \\
\hline
\end{tabular}


Table 5 Risk of bias for included studies

\begin{tabular}{|c|c|c|c|c|c|c|c|}
\hline & $\begin{array}{c}\text { Cooke } \\
2009 \\
\end{array}$ & $\begin{array}{l}\text { Donaldson } \\
2009 \\
\end{array}$ & $\begin{array}{l}\text { GAPS } \\
2004 \\
\end{array}$ & $\begin{array}{c}\text { Lincoln } \\
1999\end{array}$ & $\begin{array}{l}\text { Kwakkel } 1999 \& \\
2002 \\
\end{array}$ & $\begin{array}{l}\text { Partridge } \\
2000\end{array}$ & $\begin{array}{c}\text { Rodgers } \\
2000\end{array}$ \\
\hline Sequence generation & low & low & low & low & low & low & low \\
\hline Allocation concealment & low & low & low & unclear & unclear & low & low \\
\hline $\begin{array}{l}\text { Blinding (participants, personnel and } \\
\text { assessors) }\end{array}$ & low & low & low & low & low & low & high \\
\hline Incomplete outcome data & low & low & low & unclear & low & unclear & low \\
\hline Selective outcome reporting & low & low & low & low & low & high & low \\
\hline Other sources of bias & low & low & low & low & low & low & low \\
\hline
\end{tabular}

sizes found for individual comparisons were: Motricity Index Leg score, 23.0 [10.0,35.9]; Motricity Index Arm score, 24.1 [9.2,33.1]; knee extension torque, $17.5[1.1,33.9]$, knee flexion torque, 15.0 [3.7,26.3]; and hand grip strength, $-11.0[-20.2,-1.8]$. Meta-analysis was only possible for hand grip force/ strength ( 2 studies) and this found a benefit for the standard dose of therapy, $-10.1[-19.1,1.2]$.
At follow-up 1 the trend toward benefit for a higher dose of therapy remained but only two of the seven individual effects sizes were significant. These were both from the same study [18-20] Motricity Index Leg score, 41.0 [27.7,54.3]; and Motricity Index Arm score, $17.5[2.3,32.7]$. Meta-analysis was only possible for Motricity Index Arm score (two studies) and the effect size was $10.7[1.7,19.8]$.,

Table 6 Motor impairment - muscle function

\begin{tabular}{|c|c|c|c|c|c|c|c|c|}
\hline \multirow[t]{2}{*}{ Time-point } & \multirow[t]{2}{*}{ Study } & \multirow[t]{2}{*}{ Measure used } & \multicolumn{2}{|c|}{ Augmented therapy } & \multicolumn{2}{|c|}{ Standard therapy } & \multicolumn{2}{|c|}{ Mean difference } \\
\hline & & & $\begin{array}{l}\text { Number } \\
\text { subjects }\end{array}$ & Mean (SD) & $\begin{array}{l}\text { Number } \\
\text { subjects }\end{array}$ & Mean (SD) & $\begin{array}{l}\text { Effect } \\
\text { size }\end{array}$ & {$[95 \% \mathrm{Cl}]$} \\
\hline \multicolumn{9}{|l|}{ Outcome } \\
\hline 4 weeks after start therapy & GAPS & Motricity arm + leg & 33 & $119.0(46.0)$ & 34 & $111.0(45.0)$ & 8.0 & {$[-13.8,29.8]$} \\
\hline 20 weeks after start therapy & Kwakkel & Motricity leg & 26 & $68.2(25.8)$ & 34 & $45.2(24.8)$ & 23.0 & {$[10.0,35.9]$} \\
\hline 20 weeks after start therapy & Kwakkel & Motricity arm & 29 & $53.1(32.0)$ & 34 & $28.9(28.5)$ & 24.2 & {$[9.2,33.1]$} \\
\hline 6 weeks after start therapy & Donaldson & Hand grip force & 10 & $71.9(49.5)$ & 8 & $64.8(39.3)$ & 7.1 & {$[-34.0,48.1]$} \\
\hline \multirow[t]{2}{*}{5 weeks after start therapy } & Lincoln & Hand grip strength & 87 & 0 (25.19) & 90 & $11.0(36.3)$ & -11.0 & {$[-20.2,-1.8]$} \\
\hline & \multicolumn{2}{|c|}{$\begin{array}{l}\text { Subtotal - hand grip force/ } \\
\text { strength }\end{array}$} & 97 & & 98 & & -10.1 & {$[-19.1,-1.2]$} \\
\hline 6 weeks after start therapy & Donaldson & Pinch grip force & 10 & $31.5(23.1)$ & 8 & $24.5(19.7)$ & 7.0 & {$[-12.8,26.8]$} \\
\hline 6 weeks after start therapy & Donaldson & Elbow extend force & 10 & $64.5(44.6)$ & 8 & $68.6(39.6)$ & -4.1 & {$[-43.1,34.8]$} \\
\hline 6 weeks after start therapy & Donaldson & Elbow flexion force & 10 & $76.1(58.7)$ & 8 & $75.0(38.7)$ & 1.1 & {$[-44.1,46.3]$} \\
\hline 6 weeks after start therapy & Cooke & $\begin{array}{l}\text { Knee extend } \\
\text { torque }\end{array}$ & 26 & $45.3(33.2)$ & 25 & $27.8(26.3)$ & $17.5^{\mathrm{a}}$ & {$[1.1,33.9]$} \\
\hline 6 weeks after start therapy & Cooke & Knee flexion torque & 26 & $34.0(23.1)$ & 25 & $19.0(17.8)$ & $15.0^{\mathrm{a}}$ & {$[3.7,26.3]$} \\
\hline \multicolumn{9}{|l|}{ Follow-up 1} \\
\hline 3 months after start therapy & GAPS & Motricity arm + leg & 32 & $130.0(44.0)$ & 33 & $120.0(42.0)$ & 10.0 & {$[-10.9,30.9]$} \\
\hline 26 weeks after start therapy & Kwakkel & Motricity leg & 26 & $68.2(25.3)$ & 34 & $27.2(26.8)$ & 41.0 & {$[27.7,54.3]$} \\
\hline 26 weeks after start therapy & Kwakkel & Motricity arm & 29 & $48.6(31.1)$ & 34 & $31.1(30.1)$ & 17.5 & {$[2.3,32.7]$} \\
\hline \multirow[t]{2}{*}{3 months after stroke } & Rodgers & Motricity arm & 54 & $85.0(20.0)$ & 51 & $78.0(36.3)$ & 7.0 & {$[-4.3,18.3]$} \\
\hline & \multicolumn{2}{|c|}{ Subtotal - Motricity arm } & 83 & & 85 & & 10.7 & {$[1.7,19.8]$} \\
\hline 18 weeks after start therapy & Cooke & $\begin{array}{l}\text { Knee extend } \\
\text { torque }\end{array}$ & 19 & $56.4(36.3)$ & 18 & $37.9(27.8)$ & $18.5^{\mathrm{a}}$ & {$[-2.3,39.3]$} \\
\hline 18 weeks after start therapy & Cooke & $\begin{array}{l}\text { Knee flexion } \\
\text { torque }\end{array}$ & 19 & $41.7(28.8)$ & 18 & $25.2(22.9)$ & $16.5^{\mathrm{a}}$ & {$[-0.2,33.2]$} \\
\hline 3 months after start therapy & Lincoln & Hand grip strength & 84 & $9.0(28.2)$ & 84 & $19.0(43.0)$ & -10.0 & {$[-19.5,1.8]$} \\
\hline \multicolumn{9}{|c|}{ Follow-up 2} \\
\hline 6 months after start therapy & Lincoln & Hand grip strength & 81 & $23.0(40.7)$ & 81 & $25.0(45.2)$ & -2.0 & {$[-15.3,11.3]$} \\
\hline 6 months after stroke & Rodgers & Motricity arm & 48 & $83.0(28.2)$ & 48 & $77.0(25.9)$ & 6.0 & {$[-4.8,16.8]$} \\
\hline 6 months after start therapy & GAPS & Motricity arm + leg & 30 & $124.0(42.0)$ & 34 & $121.0(51.0)$ & 3.0 & {$[-19.8,25.8]$} \\
\hline
\end{tabular}

${ }^{a}=$ fixed effect model used; ${ }^{b}=$ random effect model used; FU $=$ Follow-up; ${ }^{*}=<0.05$. 
No significant differences were found between the two doses of therapy at follow-up 2 (three studies). Meta-analysis was not possible.

\section{Motor impairment - movement control (Table 7)}

All of the outcome measures were made at 5 or 6 weeks after the start of therapy but heterogeneity in measures used between studies prevented meta-analysis. Effect sizes were insignificant for all individual comparisons and no trends were discernable in the data.

\section{Functional activity (Table 8)}

At outcome, data from one trial relating to Rivermead Mobility Index was omitted because only 3 of 35 participants in the extra therapy group appear to have been included in the outcome data compared to all participants in the control group [22]. Therefore values provided may not have been representative of the entire group. Meta-analysis was undertaken for Action Research Arm Test (3 studies) and comfortable walking speed (2 studies) with effect sizes of $0.1(-5.7,6.0]$ and $0.3[0.1,0.5]$ respectively. For other measures, the individual study comparisons found a trend towards a better outcome with higher dose for most comparisons but this was weaker than for motor impairment- muscle function. Significance was only found in individual study comparisons in favour of extra therapy for: ability to walk at $0.8 \mathrm{~m} / \mathrm{sec}$ or more with an odds ratio of 3.9 [1.1,13.9] and maximal walking speed effect size, 0.4 $[0.1,0.7]$. A significant benefit for standard dose therapy was found for one individual study comparison for the Rivermead Gross Function score with effect size $-2.0[-3.4,-0.6]$.

At follow-up-1 meta-analysis was undertaken for Action Research Arm Test (2 studies), Rivermead Mobility Score (2 studies) and comfortable walking speed ( 2 studies) with non-significant effect sizes of $2.2[-6.0,10.4], 1.0[-0.6,2.5]$ and $0.2[-0.1,0.4]$ respectively. For other measures the significant effect sizes from individual studies were: Rivermead Arm score, $-2.0[-3.7,-0.3] ; 5$ metre walk time, -13.6 [-26.2,-1.0]; Functional Ambulation Categories, 1.0 $[0.2,1.8]$; and ability to walk at $0.8 \mathrm{~m} / \mathrm{sec}$ or more, $2.8[0.8,10.6]$.

The follow-up-2 meta-analysis (3 studies) found a significant benefit for standard dose therapy for ARAT, subtotal of $-6.4[-12.8,0.00]$. A significant benefit in favour of standard dose therapy was also found from an individual study in respect of the Rivermead Arm score with an effect size of -2.00 $[-4.0,-0.1]$. The benefit for higher dose therapy was, however, maintained for Functional Ambulation Category, $1.0[0.4,1.6]$.

\section{Discussion}

This systematic review provides limited support for the hypothesis that a higher dose of exercise-based therapy enhances motor recovery after stroke. There are some indications from the present meta-analysis for benefit from a higher dose for: comfortable walking speed; maximum walking speed; and upper limb muscle function. Meta-analysis was, however, limited by heterogeneity between studies in the measures used and therefore most estimates of effect size were derived from single studies. Those single study sample estimates that were statistically significant were mostly in favour of a higher dose of therapy. In contrast, there are also some indications from meta-analysis for benefit from a standard dose for hand grip force/strength and upper limb functional ability at outcome (Table 6) and for ARAT score at follow-up 2 (Table 8). Caution in interpretation of the results of the present review is also raised by the finding that only three of the seven included studies had all design elements assessed as low risk of bias. Clearly there are limitations to the current evidence base that restrict the provision of clear guidance for whether an increased dose of exercise-based therapy enhances recovery after stroke.

Table 7 Motor impairment - movement control

\begin{tabular}{|c|c|c|c|c|c|c|c|c|}
\hline \multirow[t]{2}{*}{ Time-point } & \multirow[t]{2}{*}{ Study } & \multirow[t]{2}{*}{ Measure used } & \multicolumn{2}{|c|}{ Augmented therapy } & \multicolumn{2}{|c|}{ Standard therapy } & \multicolumn{2}{|c|}{ Mean difference } \\
\hline & & & $\begin{array}{l}\text { Number } \\
\text { subjects }\end{array}$ & $\begin{array}{c}\text { Mean } \\
\text { (SD) }\end{array}$ & $\begin{array}{l}\text { Number } \\
\text { subjects }\end{array}$ & $\begin{array}{c}\text { Mean } \\
\text { (SD) }\end{array}$ & $\begin{array}{l}\text { Effect } \\
\text { size }\end{array}$ & {$[95 \% \mathrm{Cl}]$} \\
\hline \multicolumn{9}{|l|}{ Outcome } \\
\hline 6 weeks after start therapy & Cooke & Symmetry step time & 19 & $18.8(35.6)$ & 15 & $28.6(33.1)$ & $9.7^{a}$ & {$[-32.9,13.5]$} \\
\hline 6 weeks after start therapy & Cooke & Symmetry step length & 19 & $13.5(15.8)$ & 15 & $25.0(36.6)$ & $11.5^{\mathrm{a}}$ & {$[-31.3,8.3]$} \\
\hline \multicolumn{9}{|l|}{ Follow-up 1} \\
\hline 18 weeks after start therapy & Cooke & Symmetry step time & 19 & $19.4(29.9)$ & 14 & $23.0(23.5)$ & $3.6^{\mathrm{a}}$ & {$[-21.9,14.6]$} \\
\hline 18 weeks after start therapy & Cooke & Symmetry step length & 19 & $23.7(49.9)$ & 14 & $12.3(11.0)$ & $-11.4^{\mathrm{a}}$ & {$[-11.8,34.6]$} \\
\hline
\end{tabular}

${ }^{a}=$ fixed effect model used; ${ }^{b}=$ random effect model used; FU = Follow-up; ${ }^{*}==<0.05$

Note: symmetry values represent difference from total symmetry therefore a higher value indicates a worse outcome. 
Table 8 Effect sizes for functional activity

\begin{tabular}{|c|c|c|c|c|c|c|c|c|}
\hline \multirow[t]{2}{*}{ Time-point } & \multirow[t]{2}{*}{ Study } & \multirow[t]{2}{*}{ Measure used } & \multicolumn{2}{|c|}{ Augmented therapy } & \multicolumn{2}{|c|}{ Standard therapy } & \multicolumn{2}{|c|}{ Mean difference } \\
\hline & & & $\begin{array}{l}\text { No. } \\
\text { subjects }\end{array}$ & $\begin{array}{c}\text { Mean } \\
\text { (SD) }\end{array}$ & $\begin{array}{c}\text { No. } \\
\text { subjects }\end{array}$ & $\begin{array}{c}\text { Mean } \\
\text { (SD) }\end{array}$ & $\begin{array}{l}\text { Effect } \\
\text { size }\end{array}$ & {$[95 \% \mathrm{Cl}]$} \\
\hline \multicolumn{9}{|l|}{ Outcome } \\
\hline 6 weeks after start therapy & Donaldson & ARAT & 10 & $41.8(17.8)$ & 8 & $45.0(14.0)$ & 3.2 & {$[-17.9,11.5]$} \\
\hline 20 weeks after start therapy & Kwakkel & ARAT & 29 & $9.0(28.9)$ & 34 & $0.0(1.5)$ & 9.0 & {$[-1.5,19.5]$} \\
\hline \multirow[t]{2}{*}{5 weeks after start therapy } & Lincoln & ARAT & 87 & $1.0(25.9)$ & 90 & $5.0(28.2)$ & -4.0 & {$[-12.0,4.0]$} \\
\hline & \multicolumn{2}{|c|}{ Subtotal - ARAT } & 126 & & 132 & & 0.1 & {$[-5.7,6.0]$} \\
\hline 6 weeks after start therapy & Donaldson & 9 Hole Peg Test & 10 & $0.2(0.2)$ & 8 & $0.2(0.1)$ & $0.0^{\mathrm{a}}$ & {$[-0.1,0.1]$} \\
\hline 5 weeks after start therapy & Lincoln & 10 Hole Peg Test & 87 & $0.0(19.3)$ & 90 & $0.0(41.5)$ & $0.0^{\mathrm{a}}$ & {$[-9.5,9.5]$} \\
\hline 5 weeks after start therapy & Lincoln & Rivermead arm & 87 & $3.0(5.9)$ & 90 & $4.0(5.2)$ & -1.0 & {$[-2.6,0.6]$} \\
\hline 6 weeks after start therapy & Cooke & Rivermead mobility & 31 & $36.6(10.4)$ & 32 & $34.6(10.8)$ & 2.0 & {$[-3.2,7.2]$} \\
\hline 6 weeks after start therapy & Cooke & Walk $0.8 \mathrm{~m} / \mathrm{s}$ or more & 31 & 11 & 32 & 4 & $3.9^{c}$ & {$[1.1,13.9]$} \\
\hline 6 weeks after start therapy & Cooke & Comfort walk speed & 32 & $0.6(0.5)$ & 31 & $0.3(0.4)$ & 0.3 & {$[0.1,0.5]$} \\
\hline \multirow[t]{2}{*}{20 weeks after start therapy } & Kwakkel & Comfort walk speed & 26 & $0.7(0.5)$ & 34 & $0.4(0.4)$ & 0.3 & {$[0.1,0.5]$} \\
\hline & \multicolumn{2}{|c|}{ Subtotal - comfort walk speed } & 58 & & 65 & & 0.3 & {$[0.1,0.5]$} \\
\hline 20 weeks after start therapy & Kwakkel & Max walk speed & 26 & $0.9(0.7)$ & 34 & $0.5(0.6)$ & 0.4 & {$[0.1,0.7]$} \\
\hline 20 weeks after start therapy & Kwakkel & FAC & 29 & $4(1.5)$ & 34 & $3(2.2)$ & 1.0 & {$[0.1,2.0]$} \\
\hline 6 weeks after start therapy & Partridge & 5 metre walk time & 33 & $49.2(32.0)$ & 22 & $39.9(29.9)$ & 9.3 & {$[-7.3,25.9]$} \\
\hline 5 weeks after start therapy & Lincoln & $\begin{array}{l}\text { Rivermead Gross } \\
\text { Function }\end{array}$ & 87 & $3.0(4.4)$ & 87 & $5.0(5.2)$ & -2.0 & {$[-3.4,-0.6]$} \\
\hline \multicolumn{9}{|l|}{ Follow-up 1} \\
\hline 26 weeks after start therapy & Kwakkel & ARAT & 29 & $4.0(28.2)$ & 34 & $0.0(1.85)$ & 4.0 & {$[-6.3,14.3]$} \\
\hline \multirow[t]{2}{*}{3 months after stroke } & Rodgers & ARAT & 54 & $53.0(27.4)$ & 51 & $54.0(41.5)$ & -1.0 & {$[-14.5,12.5]$} \\
\hline & \multicolumn{2}{|c|}{ Subtotal - ARAT } & 83 & & 85 & & 2.2 & {$[-6.0,10.4]$} \\
\hline 18 weeks after start therapy & Cooke & Rivermead mobility & 28 & $36.6(9.8)$ & 23 & $39.7(5.7)$ & -3.1 & {$[-7.4,1.2]$} \\
\hline \multirow[t]{2}{*}{3 months after start therapy } & GAPS & Rivermead mobility & 32 & $9.7(3.3)$ & 34 & $8.1(3.6)$ & 1.6 & {$[-0.1,3.3]$} \\
\hline & \multicolumn{2}{|c|}{ Subtotal - Rivermead mobility } & 60 & & 57 & & 1.0 & {$[-0.6,2.5]$} \\
\hline 18 weeks after start therapy & Cooke & Comfort walk speed & 27 & $0.6(0.5)$ & 23 & $0.4(0.4)$ & 0.2 & {$[-0.1,0.5]$} \\
\hline \multirow[t]{2}{*}{26 weeks after start therapy } & Kwakkel & Comfort walk speed & 26 & $0.6(0.5)$ & 34 & $0.4(0.4)$ & 0.2 & {$[-0.0,0.4]$} \\
\hline & \multicolumn{2}{|c|}{ Subtotal - Comfort walk speed } & 59 & & 61 & & 0.2 & {$[-0.1,0.4]$} \\
\hline 3 months after stroke & Rodgers & Frenchay Arm Test & 54 & $4.0(2.2)$ & 51 & $4.0(3.7)$ & 0.0 & {$[-1.2,1.2]$} \\
\hline 3 months after start therapy & Lincoln & Rivermead arm & 84 & $3.0(5.9)$ & 84 & $5.0(5.2)$ & -2.0 & {$[-3.7,-0.3]$} \\
\hline 6 months after start therapy & Partridge & 5 metre walk time & 27 & $35.8(16.5)$ & 33 & $49.4(32.1)$ & -13.6 & {$[-26.2,-1.0]$} \\
\hline 3 months after start therapy & Lincoln & $\begin{array}{l}\text { Rivermead Gross } \\
\text { Function }\end{array}$ & 84 & $5.0(5.2)$ & 84 & $6.0(5.9)$ & -1.0 & {$[-2.7,0.7]$} \\
\hline 26 weeks after start therapy & Kwakkel & FAC & 26 & $5.0(0.7)$ & 34 & $4.0(2.2)$ & 1.0 & {$[0.2,1.8]$} \\
\hline 18 weeks after start therapy & Cooke & Walk $0.8 \mathrm{~m} / \mathrm{s}$ or more & 27 & 10 & 23 & 4 & 2.8 & {$[0.8,10.6]$} \\
\hline 26 weeks after start therapy & Kwakkel & Max walk speed & 26 & $0.9(0.7)$ & 34 & $0.6(0.6)$ & 0.3 & {$[-0.0,0.6]$} \\
\hline \multicolumn{9}{|l|}{ Follow-up 2} \\
\hline 6 months after start therapy & Lincoln & ARAT & 81 & $3.0(28.9)$ & 81 & $19.0(33.3)$ & -16.0 & {$[-25.6,-6.4]$} \\
\hline 52 weeks after start therapy & Kwakkel & ARAT & 28 & $6.0(31.3)$ & 33 & $1.0(21.1)$ & 5.00 & {$[-8.6,18.7]$} \\
\hline \multirow[t]{2}{*}{6 months after stroke } & Rodgers & ARAT & 48 & $55.0(31.9)$ & 48 & $56.0(23.7)$ & -1.0 & {$[-12.2,10.2]$} \\
\hline & Subtotal - & ARAT & 157 & & 162 & & -6.4 & {$[-12.8,0.0]$} \\
\hline 6 months after start therapy & Lincoln & 10 Hole Peg Test & 81 & $0(40.7)$ & 81 & $0(45.2)$ & 0.0 & {$[-13.3,13.3]$} \\
\hline 6 months after stroke & Rodgers & Frenchay Arm Test & 48 & $5.0(3.0)$ & 48 & $4(3.0)$ & 1.0 & {$[-0.2,2.2]$} \\
\hline 6 months after start therapy & Lincoln & Rivermead arm & 81 & $4.0(6.7)$ & 81 & $6.0(5.9)$ & -2.0 & {$[-4.0,-0.1]$} \\
\hline 6 months after start therapy & Lincoln & $\begin{array}{l}\text { Rivermead Gross } \\
\text { Function }\end{array}$ & 81 & $6.0(5.9)$ & 81 & $7.0(3.7)$ & -1.0 & {$[-2.5,0.5]$} \\
\hline 52 weeks after start therapy & Kwakkel & Max walk speed & 25 & $0.9(0.6)$ & 33 & $0.7(0.6)$ & 0.2 & {$[-0.1,0.5]$} \\
\hline 52 weeks after start therapy & Kwakkel & FAC & 25 & $5(0.7)$ & 33 & $4(1.48)$ & 1.0 & {$[0.4,1.6]$} \\
\hline 6 months after start therapy & GAPS & Rivermead mobility & 30 & $10.2(3.1)$ & 34 & $9.1(4.0)$ & 1.1 & {$[-0.6,2.8]$} \\
\hline 52 weeks after start therapy & Kwakkel & Comfort walk speed & 25 & $0.6(0.5)$ & 33 & $0.5(0.4)$ & 0.1 & {$[-0.1,0.3]$} \\
\hline
\end{tabular}

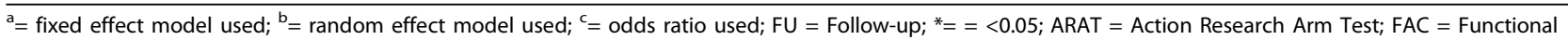
Ambulation Category. 
This finding differs from the results of benefit from extra therapy of: earlier systematic reviews [1-5] and experimental human studies (for example [12]). But, maybe this result is not so surprising considering that animal model studies and a clinical trial found that higher doses of therapy produced worse outcomes early after stroke [6-10]. Interestingly the detrimental effect found in the present systematic review on hand grip force/strength (Table 6) and upper limb function as measured by the ARAT (Table 8 ) emanate from trials conducted early after stroke $[21,24]$. It is possible therefore that there is a negative interactional effect between time from stroke and dose. However, other trials included in the present review were also conducted with participants early after stroke and detrimental effects were not found for either upper limb or lower limb motor impairment or activity. Prospective robust clinical trials are needed to investigate whether time after stroke influences motor response to different doses of exercisebased therapies.

A starting dose for subsequent trials is suggested by an earlier systematic review which concluded that a 16hour difference in treatment time between experimental and control groups provided in the first 6 months after stroke is needed to obtain significant differences in activities of daily living" [3]. Investigation of the data reported here for a potential dose-response relationship is limited by the relatively small number of comparisons that can be included in a meta-analysis because of the variation in measures used in included studies. We were concerned to avoid undertaking analyses of sets of heterogeneous measures in a single meta-analysis. However, visual inspection of outcome time-point data (Tables 6,7 and 8 ) and data on dose (Table 4) suggests a trend for better outcome with higher dose. The highest doses, however, were of task-specific interventions [18-20] whereas the smaller doses consisted of UK conventional physical therapy $[25,26]$. This difference could have influenced the results of the present review. It is also possible that differences in effect sizes between studies could be due to differences in underlying standard care. The study by Kwakkel and colleagues [18-20] was conducted in the Netherlands whereas the other four studies took place in the United Kingdom. This could have influenced the results of the present review because there may be important differences in underlying routine care between centres and countries [27]. There may also be differences in standard therapy over time [28]. Therefore the differences in clinical setting for studies may also be influential on outcome. Consequently, this present review which restricted included studies to those investigating different doses of the same therapy to avoid the confound of different types of therapy may itself be confounded by the inclusion of different types as well as different intensities of therapy. Essentially this systematic review highlights the need for prospective dose-ranging studies of specific interventions before undertaking efficacy studies.

None of the doses investigated in included studies emerged from preliminary dose-finding studies. The same observation emerged from in a systematic review and meta-analysis of electrostimulation [29]. Indeed dose-finding has not featured prominently as a precursor to stroke rehabilitation trials [30,31] Without precursor dose-finding studies it is possible that the studies included in this review investigated sub-optimal doses of exercise-based therapies. The case for prospective dosefinding studies as precursors to Phase II and phase III trials of rehabilitation has been made already [30,31]. Nevertheless, we are aware of only one study designed to investigate the relative efficacy of three or more doses of the same rehabilitation therapy [Hunter SM, Hammett L, Ball S, Smith N, Anderson C, Clark A, Tallis R, Rudd A, Pomeroy VM. Appropriate dose of Mobilisation and Tactile Stimulation to enhance upper limb recovery early after stroke: a randomised controlled trial. Submitted]. Dose-finding has not featured prominently as a precursor to phase II and phase III trials of rehabilitation therapies.

A potential limitation to the present review is the examination of multiple data sets from the same study participants. Therefore bias is potentially present through the repeated use of results arising from the same group of participants. In recognition of this possibility the present review did not combine data from the same studies within meta-analyses.

Another potential limitation is that the present review may be influenced by a publication bias as the literature search excluded studies written in a language other than English. A strong publication bias is, however, unlikely to be present the studies included in this present review were also included in previous meta-analyses. In addition, authors of included studies were contacted for any unpublished data.

\section{Conclusions}

The findings indicate that there is limited empirical evidence to inform clinical decisions on how much exercise-based therapy is needed to enhance motor recovery after stroke. To the best of our knowledge the present systematic review of the effects of dose of therapy is the first to control for the potential confounder of different types of intervention. It has refined and updated knowledge of the effects on motor recovery of the provision of an increased dose of exercise-based therapy after stroke. It has highlighted the clinical uncertainty around dose. Further systematic reviews are unlikely to resolve this clinical uncertainty because 
of the heterogeneity between exercise-based therapies in included studies and the apparent lack of dose-finding studies undertaken as precursors to robust clinical trials. The results of the present systematic review therefore indicate a need to undertake dose-finding studies of specific exercise-based interventions as precursors to robust clinical trials.

\section{Acknowledgements}

We gratefully acknowledge: funding provided by The Healthcare Foundation and St George's Charitable Foundation that enabled us to undertake this study.

\section{Author details}

'St George's University of London, Academic Dept of Geriatric Medicine, London SW17 ORE, UK. ${ }^{2}$ Health and Social Sciences Research Institute, Queen's Building, University of East Anglia, Norwich, NR4 7TJ, UK. ${ }^{3}$ Health and Social Sciences Research Institute, MED Building, University of East Anglia, Norwich, Norfolk, NR4 7TJ, UK. ${ }^{4} 7$ Valley Road, Bramhall, Cheshire, SK7 $2 \mathrm{NH}, \mathrm{UK}$.

\section{Authors' contributions}

Dr Cooke has made substantial contributions to conception and design, acquisition of data, analysis and interpretation of data, revision of manuscript, and has given final approval of the version to be published. Kathyrn Mares has made substantial contributions to acquisition of data, analysis and interpretation of data, revision of manuscript and has given final approval of the version to be published.

Dr Clark has made substantial contributions to analysis and interpretation of data, revision of manuscript, and has given final approval of the version to be published.

Professor Tallis has made substantial contributions to conception and design, revision of manuscript, and has given final approval of the version to be published.

Professor Pomeroy has made substantial contributions to conception and design, acquisition of data, analysis and interpretation of data, revision of manuscript, and has given final approval of the version to be published.

\section{Competing interests}

We gratefully acknowledge: funding provided by The Healthcare Foundation and St George's Charitable Foundation that enabled us to undertake this study. The authors declare that they have no other competing interests.

Received: 21 September 2010 Accepted: 13 October 2010

Published: 13 October 2010

\section{References}

1. Langhorne P, Wagenaar R, Partridge C: Physiotherapy after stroke: more is better? Physiotherapy Research International 1996, 1:75-88.

2. Kwakkel G, Wagenaar RC, Koelman TW, Lankhorst GJ, Koetsier JC: Effects of intensity of rehabilitation after stroke. A research synthesis. Stroke 1997, 28:1550-1556.

3. Kwakkel G, van Peppen R, Wagenaar RC, Wood-Dauphinee S, Richards C, Ashburn A, Miller K, Lincoln N, Partridge C, Wellwood I, Langhorne P: Effects of augmented exercise therapy time after stroke. A meta analysis. Stroke 2004, 35:2529-2536.

4. Van Peppen RPS, Kwakkel G, Wood-dauphinee S, Hendricks HJM, Van der Wees PhJ, Dekker J: The impact of physical therapy on functional outcomes after stroke. What's the evidence? Clinical Rehabilitation 2004, 18:833-862.

5. Galvin R, Murphy B, Cusack T, Stokes E: The impact of increased duration of exercise therapy on functional recovery following stroke - what is the evidence? Topics in Stroke Rehabilitation 2008, 15:365-377.

6. Dromerick AW, Lang CE, Birkenmier RL, Wagner JM, Miller JP, Videen TO, Powers WJ, Wolf SL, Edwards DF: Very early constraint-induced movement during stroke rehabilitation (VECTORS). Neurology 2009, 73:195-201.
7. Kozlowski DA, James DC, Schallert T: Use-dependent exaggeration of neuronal injury after unilateral sensorimotor cortex lesions. The Journal of Neuroscience 1996, 16:4776-4786.

8. Humm JL, Kozlowski DA, Bland ST, James DC, Schallert T: Use-dependent exaggeration of brain injury: is glutamate involved? Experimental Neurology 1999, 157:349-358.

9. Bland S, Schallert T, Strong R, Aronowski J, Grotta JC: Early exclusive use of the affected forelimb after moderate transient focal ischemia in rats. Functional and anatomical outcome. Stroke 2000, 31:1144-1152.

10. Risedal A, Zeng J, Johansson BB: Early training may exacerbate brain damage after focal brain ishemia in the rat. Journal of Cerebral Blood Flow and Metabolism 1999, 19:997-1003.

11. Biernaskie J, Corbett D: Enriched rehabilitative training promotes improved forelimb motor function and enhanced dendritic growth after focal ischemic injury. The Journal of Neuroscience 2001, 21:5272-5280.

12. Nugent JA, Schurr KA, Adams RD: A dose-response relationship between amount of weight-bearing exercise and walking outcome following cerebrovascular accident. Arch Phys Med Rehabil 1994, 75:399-402.

13. Byl NN, Pitsch EA, Abrams GM: Functional outcomes can vary by dose: learning-based sensorimotor training for patients stable poststroke. Neurorehabilitation \& Neural Repair 2008, 22:494-504.

14. Sterr A, Elbert T, Berthold I, Kolbel B, Taub E: Longer versus shorter daily constraint-induced movement therapy of chronic hemipareis an exploratory study. Arch Phys Med Rehabil 2002, 83:1374-1377.

15. Cooke E: The effects of type and intensity of physiotherapy on strength and function after stroke. PhD Thesis St. George's, University of London.

16. Kwakkel G: Impact of intensity of practice after stroke: issues for consideration. Disability and Rehabilitation 2006, 28:823-830.

17. Higgins JPT, Altman DG: Cochrane handbook for systematic reviews of interventions Version 5.02 (updated September 2009). The Cochrane Collaboration 2008 [http://www.cochrane-handbook.org].

18. Kwakkel G, Wagenaar RC, Twisk JWR, Lankhorst GJ, Koetsier JC: Intensity of leg and arm training after primary middle-cerebral-artery stroke: a randomized trial. The Lancet 1999, 354:191-196.

19. Kwakkel G, Kollen BJ, Wagenaar RC: Long term effects of intensity of upper and lower limb training after stroke: a randomised trial. I Neurol Neurosurg Psychiatry 2002, 72:473-479.

20. Kwakkel G: Dynamics in functional recovery after stroke. Proefschrift Vrije Universiteit Amsterdam 1998, ISBN 9080449717.

21. The Glasgow Augmented Physiotherapy Study (GAPS) Group: Can augmented physiotherapy input enhance recovery of mobility after stroke? A randomized controlled trial. Clinical Rehabilitation 2004, 18:529-537.

22. Lincoln NB, Parry RH, Vass CD: Randomized, controlled trial to evaluate increased intensity of physiotherapy treatment of arm function after stroke. Stroke 1999, 30:573-579.

23. Partridge C, Mackenzie M, Edwards S, Reid A, Jayawardena S, Guck N, Potter J: Is dosage of physiotherapy a critical factor in deciding patterns of recovery from stroke: a pragmatic randomized controlled trial. Physiotherapy Research International 2000, 5:230-240.

24. Rodgers H, Mackintosh J, Price C, Wood R, Mcnamee P, Fearon T, Marritt A, Curless $R$ : Does an early increased-intensity interdisciplinary upper limb therapy programme following acute stroke improve outcome? Clinical Rehabilitation 2003, 17:579-589.

25. Donaldson C, Tallis R, Miller S, Sunderland A, Lemon R, Pomeroy VM: Effects of conventional therapy and functional strength training on upper limb motor recovery after stroke: a randomized Phase II study. Neurorehabilitation and Neural Repair 2009, 2:389-397.

26. Cooke EV, Tallis RC, Clark A, Pomeroy VM: Efficacy of functional strength training on restoration of lower-limb motor function early after stroke: Phase ! randomized controlled trial. Neurorehabilitation and Neural Repair 2010, 24:88-96.

27. Putman K, De Wit L, Schupp W, Ilse B, Berman P, Connell L, Dejager E, De Meyer A-M, De Weerdt W, feys $H$, Walter J, Bincoln N, Louckx F, Anneleen M, Birgit S, Smith B, Leys M: Use of time by physiotherapists and occupational therapists in a stroke rehabilitation unit: a comparison between four European rehabilitation centres. Disability and Rehabilitation 2006, 28:1417-1424.

28. Turner PA, Whitfield TA: Physiotherapists' reasons for selection of treatment techniques: A cross-national survey. Physiotherapy Theory and Practice 1999, 15:235-246. 
29. Pomeroy VM, King L, Pollock A, Baily-Hallam A, Langhorne P:

Electrostimulation for promoting recovery of movement or functional ability after stroke. The Cochrane Database of Systematic Reviews 2006, , 2: CD003241. pub2.

30. Dobkin BH: Progressive staging of pilot studies to improve Phase III trials for motor interventions. Neurorehabilitation \& Neural Repair 2009, 23:197-206.

31. Pomeroy VM, Tallis RC: Need to focus research in stroke rehabilitation. Lancet 2000, 355:836-837.

\section{Pre-publication history}

The pre-publication history for this paper can be accessed here: http://www.biomedcentral.com/1741-7015/8/60/prepub

doi:10.1186/1741-7015-8-60

Cite this article as: Cooke et al: The effects of increased dose of exercise-based therapies to enhance motor recovery after stroke: a systematic review and meta-analysis. BMC Medicine 2010 8:60.

\section{Submit your next manuscript to BioMed Central} and take full advantage of:

- Convenient online submission

- Thorough peer review

- No space constraints or color figure charges

- Immediate publication on acceptance

- Inclusion in PubMed, CAS, Scopus and Google Scholar

- Research which is freely available for redistribution

Submit your manuscript at www.biomedcentral.com/submit 